\title{
Resonant coaxial SMA microwave permittivity sensor
}

\author{
Dusan Nesic ${ }^{1}$, Tomislav Milosevic ${ }^{2}$
}

\begin{abstract}
Resonant coaxial SMA microwave permittivity sensor is introduced. It is constructed using only commercially available SMA connectors. The sensor is tested in two different frequency ranges for two different dielectric constant ranges, from 1 to 10 and from 10 to 80. Presented sensor is designed, fabricated, simulated, and tested. Good agreement between simulations and measurements is shown. The sensor is also applicable for differential permittivity measurements.

K e y w or d s: microwave sensor, resonant coaxial SMA sensor, differential permittivity measurement.
\end{abstract}

\section{Introduction}

Microwave sensors become a widespread type of sensors $[1-3]$. Among them permittivity sensors are important in characterization of microwave substrates and materials such gasses, fluids, and solids [2-4]. The resonant method, as a type of permittivity sensing, has some advantages over the other methods. The resonant method enables the lowest uncertainty for the permittivity determination [2] while the permittivity is determined from measurements of the resonance frequency.

Application of coaxial structures in sensing represents foundation for one of the most convenient and frequently used techniques to measure lossy materials at high frequencies (ie radio and microwave frequencies). The most common method relying on coaxial structures is coaxial probe method which detects reflected signal (phase and magnitude) from the tested material [3]. The method is applicable to fluid measurements. However, it has some disadvantages. The disadvantages are: repetitive calibrations required, the reflections for the low permittivity materials and required stability of cables $[3,4]$.

Another coaxial method used to measure the dielectric properties of fluids is a method based on usage of coaxial open stub $\lambda_{\mathrm{g}} / 4$ (or coaxial shorted $\lambda_{\mathrm{g}} / 2$ ) resonator [58 . This technique is less sensitive to errors, especially for the errors produced by electromagnetic interference.

In all cases found in [5-8] the measurement systems are used with relatively high amount of fluids, mainly for water monitoring. In these cases, diameter of open stub is around $25 \mathrm{~mm}$ while length over $250 \mathrm{~mm}$.

A general drawback of resonance-based sensors is that permittivity depends on environmental conditions such is temperature or moisture and thus the resonance frequency can be shifted by spurious effects. Typical solu- tion to beat the environmental factors is through differential measurements $e g$ through usage of differential sensor. Also, the differential permittivity sensors are not rare for planar sensors [9]. As far as the authors of this paper know, there is no differential coaxial sensor described in the literature.

SMA coaxial resonant open stub $\lambda_{\mathrm{g}} / 4$ permittivity sensor presented in this paper is intended for testing a small amount of material. It is constructed using only commercially available SMA connectors. The applied SMA connectors are two SMA jack-to-jack-to-jack Tee adapters and two plug-to-jack adapters. The sensor is fabricated, simulated, and preliminary measured in a wide range of relative dielectric constant. The structure is also obtained for the differential permittivity measurement.

\section{Sensor construction}

The presented sensor in Fig. 1 is constructed using two SMA jack-to-jack-to-jack Tee adapters (A) and two SMA plug-to-jack adapters (B) connected with one SMA plugto-plug adapter $(\mathrm{C})$. A copper wire which is $12.3 \mathrm{~mm}$ long is mounted on each Tee adapter as a central conductor of the open stub. It is shown in Fig. 1(a). The inner content of the both SMA plug-to-jack adapter (B) is removed and one hollow metal cylinder is mounted on each Tee adapter with the wire, Fig. 1(a), forming the final structure shown in Fig. 1(b). Now, both open stubs are formed in such manner that they contain the wire (the central conductor shown in Fig. 1a) and the hollow SMA plug-to-jack adapter which represents the outer conductor, Fig. 1(b). The hollow SMA plug-to-jack adapter marked with (B) in Fig. 1(b), is filled with fluid which represents material under test (MUT).

\footnotetext{
${ }^{1}$ Centre of Microelectronic Technologies, Institute of Chemistry, Technology and Metallurgy, University of Belgrade, Njegoseva 12, Belgrade, Serbia, ${ }^{2}$ WIPL-D d.o.o., Gandijeva 7, 11073, Belgrade, Serbia, tomislav.milosevic@wipl-d.com, * Corresponding author: nesicad@nanosys.ihtm.bg.ac.rs
}

DOI:10.2478/jee-2020-0039, Print (till 2015) ISSN 1335-3632, On-line ISSN 1339-309X

(C) This is an open access article licensed under the Creative Commons Attribution-NonCommercial-NoDerivs License (http: //creativecommons.org/licenses/by-nc-nd/3.0/). " 

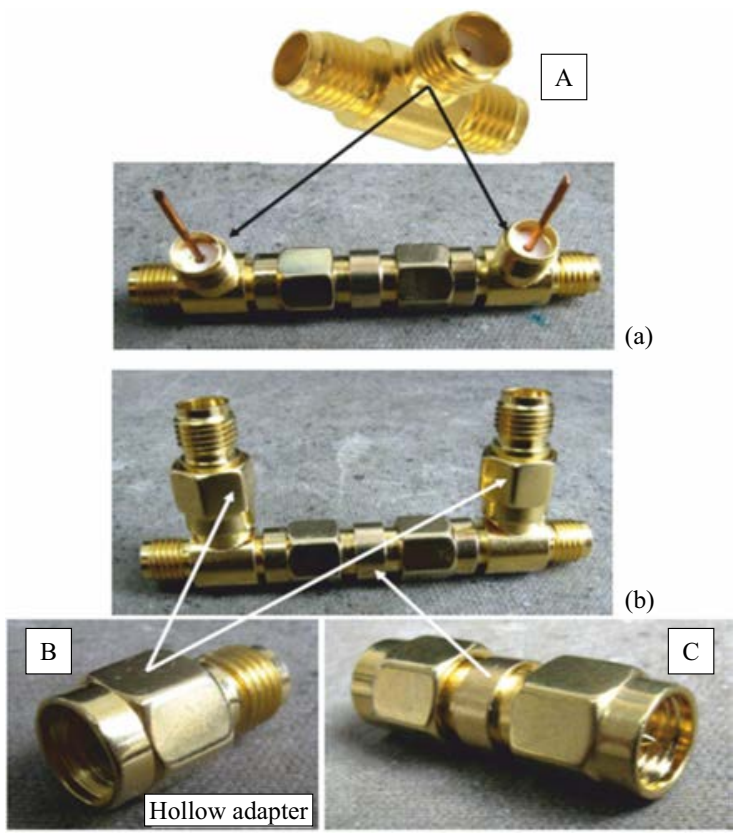

Fig. 1. (a) - structure without the hollow adapter, (b) - with the hollow adapter: A-SMA jack-to-jack-to-jack tee adapter; B-SMA plug-to-jack adapter; C-SMA plug-to-plug adapter
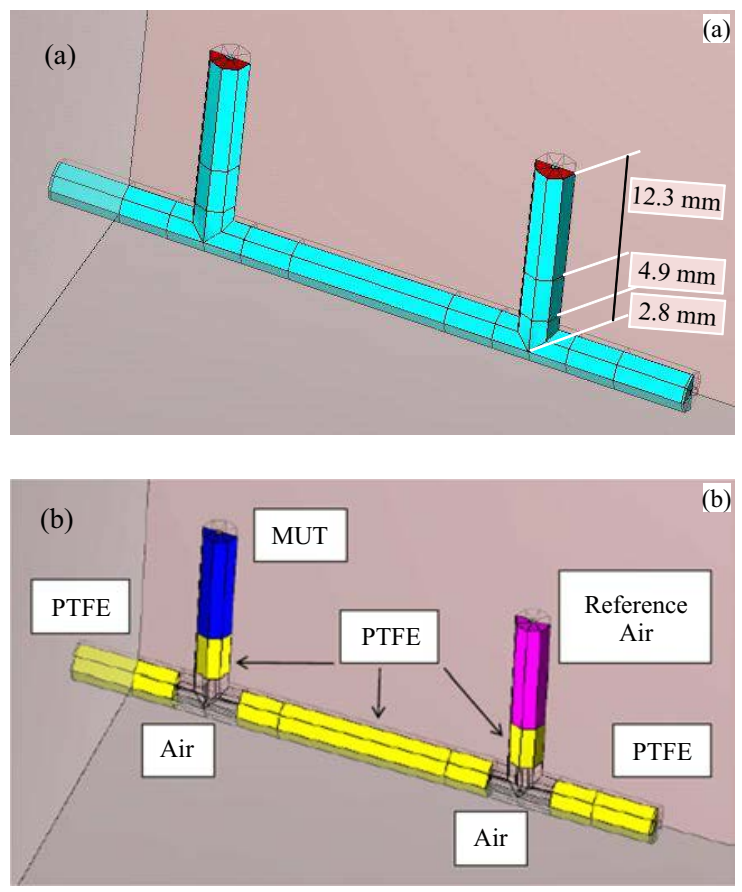

Fig. 2. Preview of the sensor modeled in WIPL-D pro software suite

\section{Simulation and measurement}

Simulation is performed in WIPL-D Pro software suite [10]. The WIPL-D Pro model of the sensor is presented in Fig. 2 in two ways: showing outer coaxial metal conductor and dimensions of two $\lambda_{\mathrm{g}} / 4$ resonators, Fig. 2(a) and dielectric materials filling the SMA adapters: MUT-material under test, reference air, airhollow area inside SMA jack-to-jack-to-jack tee adapter, Fig. 2(b).

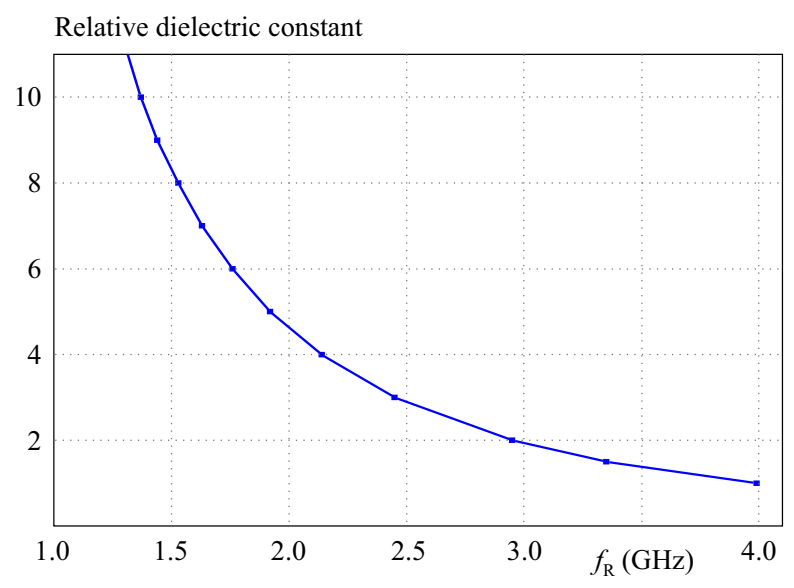

Fig. 3. Calibration $\varepsilon_{\mathrm{R}}-f_{\mathrm{r}}$ curve for the lower range of relative dielectric $\operatorname{constant}\left(\varepsilon_{\mathrm{R}}\right.$ is between 1 and 10)

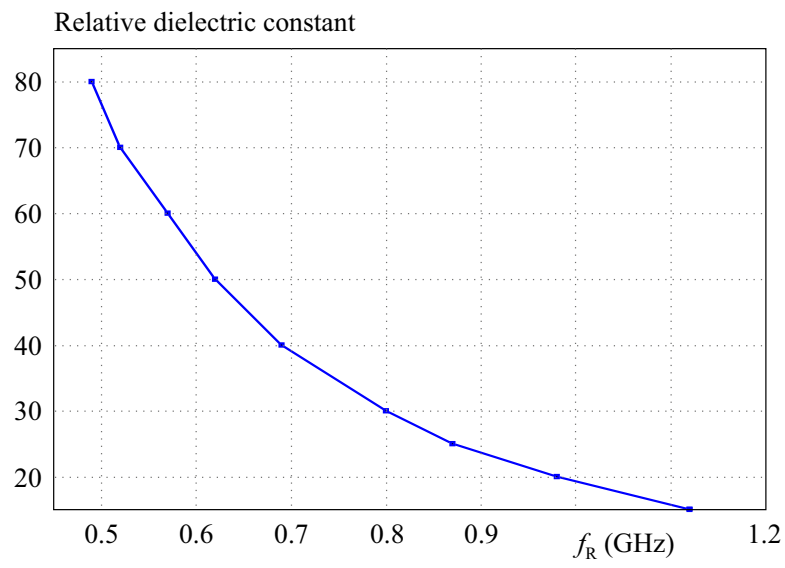

Fig. 4. Calibration $\varepsilon_{\mathrm{R}}$-fr curve for the higher range of relative dielectric $\operatorname{constant}\left(\varepsilon_{\mathrm{R}}\right.$ is between 10 to 80$)$

Table 1. Measured and referent values of $\varepsilon_{\mathrm{R}}$ for simulated MUTs

\begin{tabular}{|c|c|c|c|c|c|}
\hline \multirow{2}{*}{ MUT } & \multicolumn{2}{|c|}{ Measured $\pm 5 \mathrm{MHz}$} & \multirow{2}{*}{ Ref } & \multirow{2}{*}{$\varepsilon_{\mathrm{R}}$} & \multirow{2}{*}{$\begin{array}{l}\text { error } \\
(\%)\end{array}$} \\
\hline & $\varepsilon_{\mathrm{R}}$ & $f_{\mathrm{R}}(\mathrm{GHz})$ & & & \\
\hline Gasoline & $1.96 \pm 0.01$ & 2.98 & {$[12]$} & 2.0 & 2 \\
\hline Paraffin oil & $2.1 \pm 0.01$ & 2.88 & [13] & 2.2 & 5 \\
\hline Water $*$ & $80.0 \pm 2$ & 0.49 & {$[11]$} & 80.0 & 1 \\
\hline Ethanol $70 \%$ & $43.0 \pm 1$ & 0.66 & [14] & 40.0 & 7.5 \\
\hline
\end{tabular}

* water from the regular water supply, near $20^{\circ} \mathrm{C}$

The resonant frequencies (calibration curves) for the given MUT $\varepsilon_{\mathrm{R}}$ according to simulation are presented in Fig. 3 and Fig. 4. Figure 3 assumes lower real dielectric constant $\varepsilon_{\mathrm{R}}$ (1 to 10$)$ while Fig. 4 assumes higher $\varepsilon_{\mathrm{R}}$ (10 to 80 ). The air $\varepsilon_{\mathrm{R}}$ is considered to be 1 while PTFE $\varepsilon_{\mathrm{R}}$ equal to 2.1 is used. In real life measurements, materials under test with lower $\varepsilon_{\mathrm{R}}$ values are usually gasoline and oils. Materials under test with higher $\varepsilon_{\mathrm{R}}$ values include ethanol, water, and their mixture. 
$S_{21}(5 \mathrm{~dB} / \mathrm{div})$

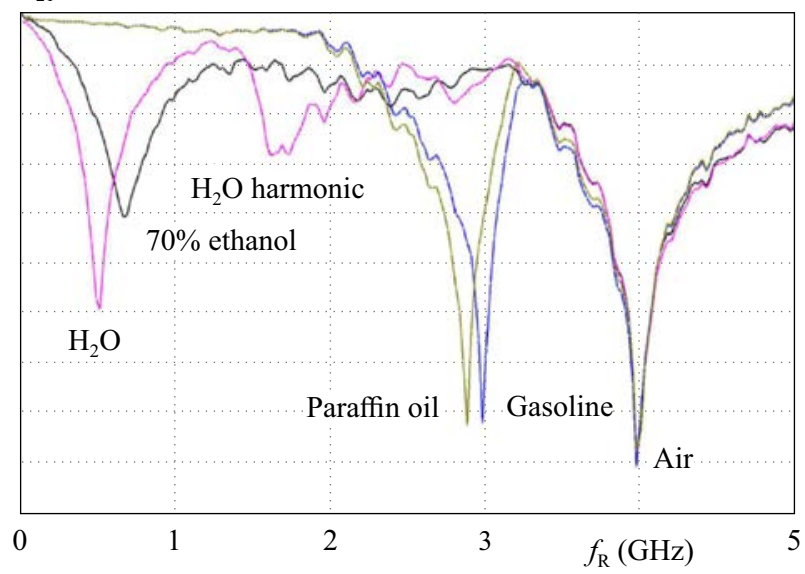

Fig. 5. Measured $S_{21}$ parameters for air, gasoline, paraffin oil, $70 \%$ ethanol-water mixture and tap water

\section{Relative sensitivity $\mathrm{d} \varepsilon_{\mathrm{R}} / \mathrm{d} f / \varepsilon_{\mathrm{R}}(1 / \mathrm{GHz})$}

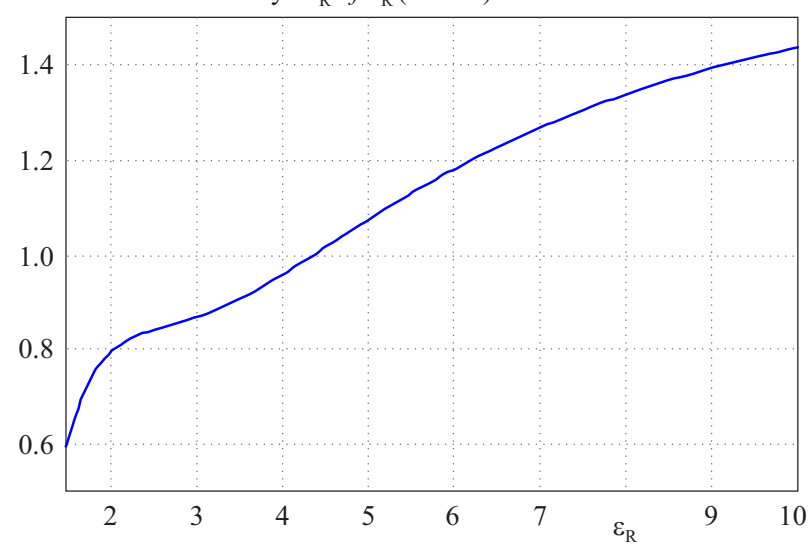

Fig. 6. Relative sensitivity in the lower range of relative dielectric constant $\left(\varepsilon_{\mathrm{R}}\right.$ is between 1 to 10$)$

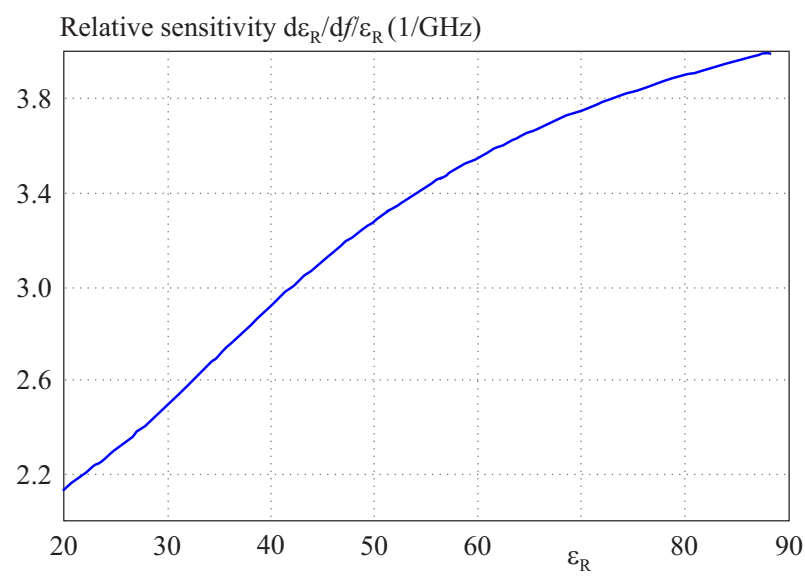

Fig. 7. Relative sensitivity in the higher range of relative dielectric constant $\left(\varepsilon_{\mathrm{R}}\right.$ is between 20 to 80$)$

Preliminary measured results are presented for air, gasoline, paraffin oil, $70 \%$ ethanol-water mixture, and tap water in Fig. 5, the resonant frequencies $f_{\mathrm{R}}$ are clearly visible. Higher harmonic resonances can be recognized if water is used as MUT. The second resonance is somewhat shifted from $3 f_{\mathrm{R}}$ and have a wider bandgap. The reason is lower dielectric constant and higher losses for higher frequencies in the case of water [11].

Relative sensitivity $\left.-\left(\mathrm{d} \varepsilon_{\mathrm{R}} / \mathrm{d} f\right) / \varepsilon_{\mathrm{R}}\right]$ is calculated from the fitting curves and presented in Fig. 6 and Fig. 7.

Calculated values of $\varepsilon_{\mathrm{R}}$ for MUTs obtained from the calibration curves and the referent values for $\varepsilon_{\mathrm{R}}$ are presented in Table 1. Only the first resonant frequencies are listed. The resolution depends on the frequency step $( \pm 5 \mathrm{MHz})$ and on the dielectric constant range.

\section{Conclusion}

This paper represented a new type of coaxial resonant sensor. The presented coaxial resonant sensor was constructed using only SMA connectors (adapters): SMA jack-to-jack-to-jack Tee adapter and SMA plug-to-jack adapter. It offers good protection from electromagnetic interference since the outer coaxial conductor enables very good shielding. Also, it is easy for construction since it consists of commercial SMA adapters and it is very useful for smaller amount of fluid under test. The coaxial resonant sensor can also be used both as a differential sensor.

The sensor is simulated and measured for lower values of real dielectric constant ( $\varepsilon_{\mathrm{R}}$ between 1 and 10) and for higher values of dielectric constant $\left(\varepsilon_{\mathrm{R}}\right.$ between 10 and 80). All results well match values found in the available references.

\section{Acknowledgments}

Author would like to thank J. Zivkovic, L. Novaković, Dr M. Frantlović and R. ordević for assistance in fabrication and professor M. Potrebic from the University of Belgrade, School of Electrical Engineering, for her assistance in performing the measurements. This work was financially supported by Ministry of Education, Science and Technological Development of the Republic of Serbia, Grant No. 451-03-68/2020-14/200026.

\section{REFERENCES}

[1] S. Dey, J. K. Saha and, C. Karmakar, "Smart Sensing: Chipless RFID Solutions for the Internet of Everything", IEEE Microwave Magazine, vol. 16, no. 10, pp. 26-39, 2015.

[2] J. Baker-Jarvis, M. D. Janezic and, C. DeGroot, "High-Frequency Dielectric Measurements", IEEE Instrumentation \& Measurement Magazine, vol. 13, no. 2, pp. 24-31, 2010.

[3] M. T. Jilani, M. Z. ur Rehman, A. M. Khan, M. T. Khan, and S. M. Ali, "A Brief Review of Measuring Techniques for Characterization of Dielectric Materials", International Journal of Information Technology and Electrical Engineering, vol. 1, no. 1, pp. 1-5, 2012.

[4] "Agilent Basics of Measuring the Dielectric Properties of Materials", Application Note, www.agilent.com.

[5] N. A. Hoog-Antonyuk, W. Olthuis, M. J. J. Mayer, D. Yntema, H. Miedema, and A. van den Berg, "On-Line Fingerprinting of Fluids using Coaxial Stub Resonator Technology", Sensors and Actuators B: Chemical, vol. 163, no. 1, pp. 90-96, 2012. 
[6] N. A. Hoog, M. J. J. Mayer, H. Miedema, W. Olthuis, F. B. J. Leferinkd, and A. van den Berg, "Modeling and Simulations of the AmplitudeFrequency Response of Transmission Line Type Resonators Filled with Lossy Dielectric Fluids", Sensors and Actuators A: Physical, vol. 216, pp. 147-157, 2014.

[7] N. A. Hoog, M. J. J. Mayer, H. Miedema, W. Olthuis, A. A. Tomaszewska, A. H. Paulitsch-Fuchs, and A. van den Berg, "Online Monitoring of Biofouling using Coaxial Stub Resonator Technique", Sensing and Bio-Sensing Research, vol. 3, pp. 79-91, 2015.

[8] N. A. Hoog, M. J. J. Mayer, H. Miedema, W. Olthuis, and A. van den Berg, "Coaxial Stub Resonator for Online Monitoring Early Stages of Corrosion", Key Engineering Materials, vol. 605, pp. 111-114, 2014.

[9] A. Ebrahimi, G. Beziuk, J. Scott, and K. Ghorbani, "Microwave Differential Frequency Splitting Sensor Using Magnetic-LC Resonators", Sensors, vol. 20, no. 4, pp. 1-11, 2020.

[10] "Program Package WIPL-D Pro v15 WIPL-D d.o.o", Belgrade 2019, www.wipl-d.com.

[11] M. Chaplin, "Water and Microwave", http://www1.lsbu.ac.uk/water/microwave_water.html.

[12] F. S. Jafari and J. Ahmadi-Shokouh, "Reconfigurable Microwave SIW Sensor Based on PBG Structure for High Accuracy Permittivity Characterization of Industrial Liquids", Sensors and Actuators A: Physical, vol. 283, pp. 386-395, 2018.
[13] Relative Permittivity - the Dielectric Constant Engineering ToolBox, 2010, https://www.engineeringtoolbox.com/ relative-permittivity-d_1660.html.

[14] A. Megriche1, A. Belhadj, and Mgaidi, "Microwave Dielectric Properties of Binary Solvent Water-Alcohol, Alcohol-Alcohol Mixtures at Temperatures Between $-35^{\circ} \mathrm{C}$ and $+35^{\circ} \mathrm{C}$ and Dielectric Relaxation Studies", Mediterranean Journal of Chemistry, vol. 1, no. 4, pp. 200-209, 2012.

Received 11 June 2020

Dusan A. Nesić was born in Belgrade, Serbia, in 1961. He received the BSc (1987), MSc (1995), and PhD (2011) degrees in electrical engineering from the School of Electrical Engineering, University of Belgrade, Serbia. He is currently with IHTM-CMTM, University of Belgrade, Belgrade, Serbia. His research interests include passive microwave structures, microwave and millimeter antennas, sensors and photodiodes.

Tomislav S. Milosević was born in 1984 in Belgrade, Serbia. He received the BSc and MSc, degrees from the University of Belgrade, Serbia, in 2007 and 2008, respectively. In 2009, he joined WIPL-D company, where at present he works as engineer for applications and technical support. His main research interests include modeling and simulation of various EM structures. 